\title{
Pennyroyal Oil
}

National Cancer Institute

\section{Source}

National Cancer Institute. Pennyroyal Oil. NCI Thesaurus. Code C74293.

The essential oil extracted from the leaves of Mentha pulegium. Pennyroyal oil has antiseptic properties. It has been used for inducing abortions, repelling fleas and ticks, and for treating illnesses of the digestive system. 